\title{
Gesture Control Robotic Arm Using Flex Sensor
}

\author{
Waseem Afzal $^{1}$, Shamas Iqbal ${ }^{2}$, Zanib Tahira ${ }^{1}$, Mehtab Ejaz Qureshi ${ }^{1}$ \\ ${ }^{1}$ Department of Electrical Engineering, Comsat Institute of Information Technology, Lahore, Pakistan \\ ${ }^{2}$ Department of Electrical Engineering, Institute of Space Technology, Islamabad, Pakistan
}

\section{Email address:}

waseem.afzal@hup.edu.pk (W.Afzal), shamas.iqbal46@yahoo.com (S. Iqbal), zanibtahira@gmail.com (Z. Tahira), mehtab.eq@gmail.com (M. E. Qureshi)

\section{To cite this article:}

Waseem Afzal, Shamas Iqbal, Zanib Tahira, Mehtab Ejaz Qureshi. Gesture Control Robotic Arm Using Flex Sensor. Applied and Computational Mathematics. Vol. 6, No. 4, 2017, pp. 171-176. doi: 10.11648/j.acm.20170604.12

Received: March 7, 2017; Accepted: May 24, 2017; Published: July 12, 2017

\begin{abstract}
The design and implementation of a gesture control robotic arm using flex sensor is proposed. The robotic arm is designed in such a way that it consists of four movable fingers, each with three linkages, an opposing thumb, a rotating wrist and an elbow. The robotic arm is made to imitate the human hand movements using a hand glove. The hand glove consists 5 flex sensor for controlling the finger movements and an Accelerometer for the wrist and elbow movements. The actuators used for the robotic arm are servo motors. The finger movements are controlled using cables that act like the tendons of human arm. The robotic arm is controlled from a distant location using a wireless module. A prototype of the robotic arm was constructed and tested for various hand movements.
\end{abstract}

Keywords: Robotic Arm, Flex Sensor, Wireless Module, Accelerometer

\section{Introduction}

Robotics is a flourishing field in research and everyday life because of its many applications in the military (defense and transportation), industries etc. In factories robots are widely used to perform many prescribed jobs such as welding, painting and many more. Robots are also used in many other situations which are not suitable or for highly dangerous such as a bag with explosion which may explode on opening that bag a UGV with a robotic arm is the good and safe solution for this sort of problems [1], [2] similarly mixing or working with dangerous chemicals attesting weapons are also easy through robots with no dangerous of losing man precious lives in industries for removing wastes and many other type of works can be done by a human size robot known as PUMA [3]. In the past decade there are many research in the field of humanoid robots with the inventions of many technologies to control the robots which are further discussed in the paper. Generally there are two basic way to controlled the robotic arm wired and wireless both technologies have some advantages and some disadvantages as wired circuit is complex and have cannot be controlled from the long distance but it does not require extra batteries as required for wireless system. Wireless systems also have external interference whereas wired system is less interference. The cost of wired system is much less than the wireless system.

Robotic arm based on haptic technology. This robotic arm has wide range of application in military purpose, for surgery purpose and also for education aspect [4]. The structure of the arm rehabilitation training robot and simplifies the arm models and also It establishes a united dynamics model of rehabilitation robot and arm with Mechanics in Matlab/Simulink as well as analyzes the dynamics issues of the two driven joints of the robot [5]. It developed an anthropomorphic robotic arm which was very flexible and could perform dexterous hand movements. But due to flexibility there was a risk of electrical cables getting caught in the gears while in motion [6]. It also developed a 3DOF robotic arm using tendon drive and easy motor control [7]. It proposed a force magnification drive appropriate for cable driven light weight robotic arm using flexion drive and force magnification drive. The design ensured that the robotic arm automatically adapted to the shape of the object that it grasped 8. It designed a four finger gripper having four DOF, but it was costly as it required 32 independent tendons and pneumatic actuators [9]. 
The generation of the human-like manipulation motions has been implemented and also tested successfully for the 4 degrees of freedom (DOF) arm of the humanoid robot [10]. A robotic arm with four degrees of freedom is designed and is able to pick the objects with a specific weight and place them in a desired location. To facilitate the lifting of the objects, Servomotors with a torque of $11 \mathrm{~kg}$ are used [11]. The main objective of the project is to design and develop the Robot that is used to move using wireless system by recognizing hand motion that is controlled by haptic technology for virtual environment \& human-machine systems capable of haptic interaction [12]. This is an autonomous robot arm with a three dimensional reach which could automatically detect and pick an object. Then it could place it in a destination and change the orientation as specified by the user [13].

A low cost computer vision system that can be executed in a common PC equipped with low power USB web cam was one of the main objectives of our work, which has been implemented successfully. We have experimented with around 30 hand gesture images and achieved higher average precision [14]. It provides a better way to control a robotic arm using accelerometer which is more intuitive and easy to work, besides offering the possibility to control a robot by other wireless means [15]. An automated robot has been developed which works according to your hand gesture. The robot moves wirelessly according to palm gesture [16]. Development of a costeffective technology demonstrator was successfully designed to bring together the concepts of anthropomorphic manipulators, real-time distributed processing networks for micro-controllers and haptic feedback [17].

This system will reduce the hectic interfaces like keyboard, mouse or any other equipment. Hand gesture recognition technique can provide user-friendly human and machine interfaces. Lifetime of gesture recognition system is high with greater precision and with efficient size [18]. Design for an untethered motion capture system based on inertial sensing. The functionality of our system was demonstrated through experiments in tele-operating the NASA Robonaut. Our motion capture system has been presented as a cost-effective and unencumbered means for extending motion collection beyond structured environments [19].

Design a novel controller for an automated robotic arm. A discrete Proportional Integral Derivative (PID) control technique is being used to replace the complex electronic circuitry, which would greatly reduce the cost and size of the controller [20]. LABView controlled robotic arm was successfully designed. The robotic arm was found to be user friendly and the integration of accelerometer was much helpful in attaining the feedback regarding the position of the arm [21]. A robotic arm with 2DOF is designed and implemented which is to be used in a tree climbing robot, specifically for coconut tree climbing [22].

To achieve the wireless capability we use many wireless module under the IEEE standards such as ZigBee,
Bluetooth, infrared and radio packet controller may be use each of them with different ranges and data handling capabilities. In this paper we have three sections in first section we will study about the different technology adopted with its advantages and disadvantages in the second part we will study the standards for the wireless communications and in third sections we will conclude over paper.

\subsection{Controlling the Robot using Digitally Operated and Programmable Robot}

There are many ways and methods to control a robotic arm having different shapes and sizes depending upon the type of work required. It may be a Cartesian robot /Gantry robot, cylindrical robot, Spherical/Polar robot, SCARA robot (Selective Compliance Assembly Robot Arm), Articulated robot and may be are parallel robot all of above robots has different properties and function and also have totally different controlling [23].

Digitally Operated and Programmable Robot technology was invented by George Devol an American inventor in 1961 named as Unimate. It was first industrial robot used in General Motor used for die casting handling and spot welding [24], [25]. It was first robot that replace the human from industries because it was more accurately and reliably, than humans. This robot was come into being after the invention of micro-controller, DAC and ADC it was a simple robot with the program of its working fed in its micro-controller or computer attached to it. It basic drop edge was it has less degree of freedom and because of micro-controller it have less memory so large program cannot be fed in it. To get different works from the same robot we need to reprogram the whole robot but it is also a cheap and best for the industrial purpose [25].

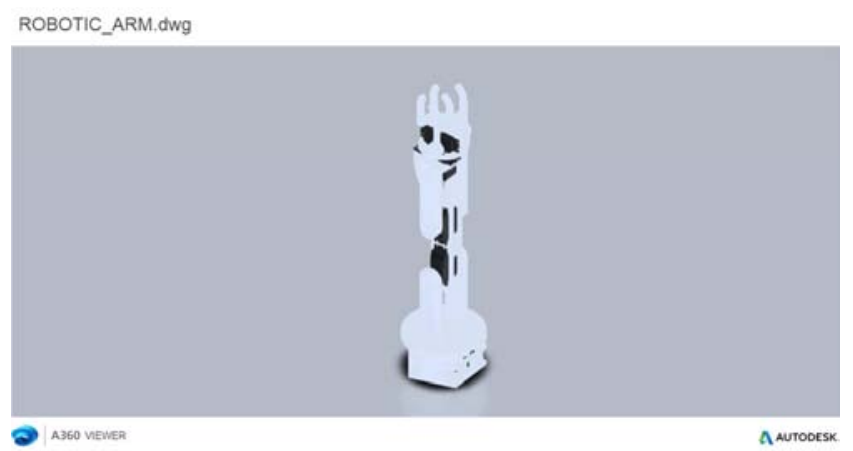

Figure 1. Digitally operated and programmable robotic arm.

\subsection{Gesture Controlled Robot}

A gesture controlled robot is type robot which may be controlled by your hand gesture, video processing, image processing, Accelerometer, Flex sensor, Kinect sensor and Mems Sensor [26]. It executes tasks with users gesture this is why it is much easy, time saving and much efficient. It is very helpful for not only for special persons but also in industries [27]. 


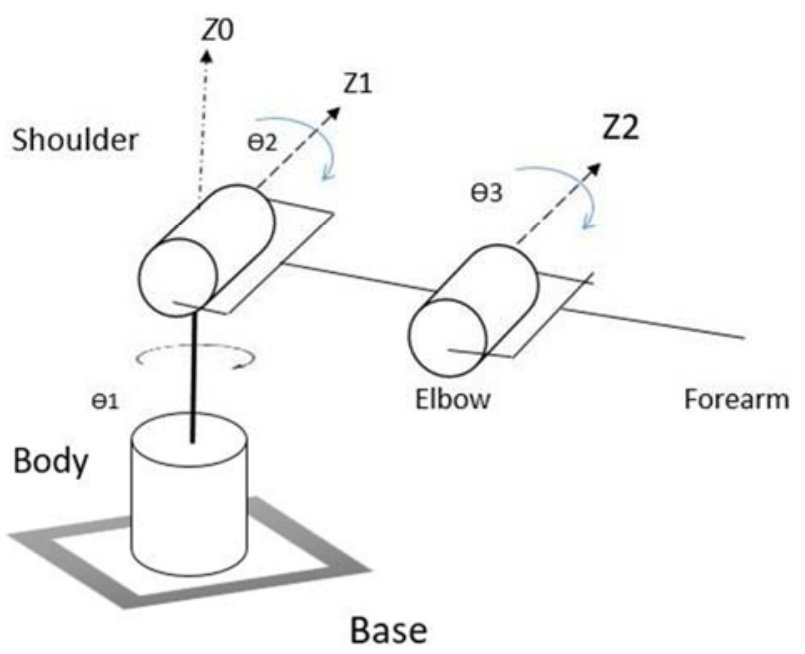

Figure 2. Gesture controlled robot.

\subsubsection{Video and Image Processing}

Video processing robot may be contain motion sensor or a camera interfacing with computer or a microcontroller having instruction of movement which was be copied by robot. It provide a simple interface for humans and provide grip as much as possible the motion generation independently.IR and Heat Sensor may also use for video processing [28]. Basic advantages are low computational complexity and less sensitive to noise. While having more time delay, costly and also required illuminated environment and limited range [29].

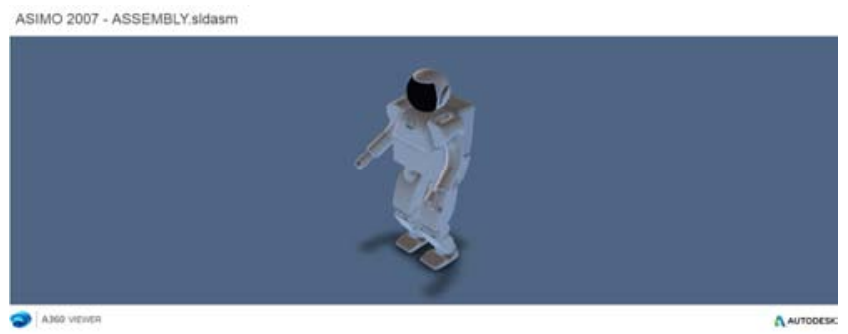

Figure 3. Video and Image Processing Robot.

\subsubsection{Flex Sensor}

Flex sensors are basically variable resistor with different ranges from $25 \mathrm{k}$ to $125 \mathrm{k}$ and sizes from 1inches to 3 inches [30]. The analog output of the flex sensors which was achieved by a part of the body having sensor must need to convert in digital form for further proceed. It is relatively very much cheaper than any other sensors and have good response, also the coding is simple than other robots. The disadvantages less sensitive and more internal and external interference, and also have unpredictable value of sensor [31].

\subsection{PC Interfaced Robot}

Pc interfaced robot are directly controlled by a computer it will connect to a pc through serial port or a parallel port and then the movement of the robot is controlled by the specially designed software or any program which was already installed in the computer. A software have the all the required controls for robot usually a micro-controller is also attached on robot the program is first fed to the microcontroller. A pc interfaced computer is usually used to perform the one type of work thus used in factories for panting, welding and etc.

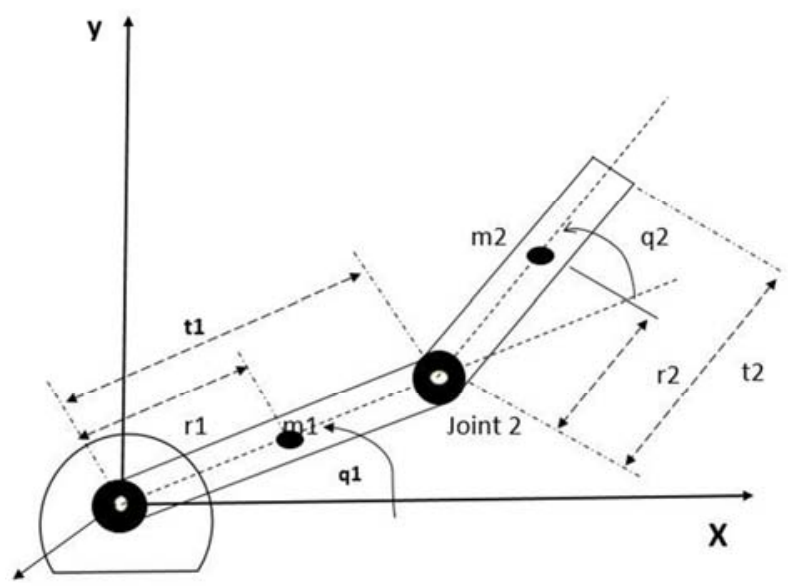

Figure 4. Flex Sensor Control Robot.

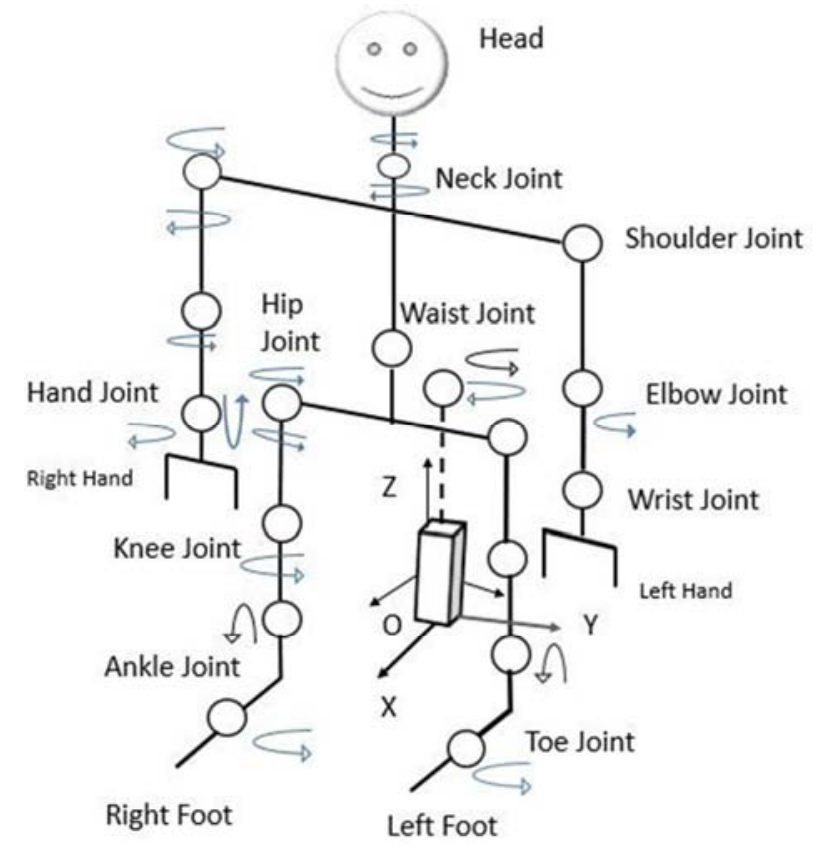

Figure 5. Gyro-Accelerometer and MEMS Sensor Robot.

\section{Methodology}

The mechanical structure of the Robotic Arm is made of easily accessible low cost plastic sheet. It design in such a way as to accommodate the actuators and the control circuit. The fingers consist of three linkages so that its movement look like that of the human finger. The opposing thumb design in such a way that it was connected to the palm using a pivot joint. Then it moves like a human thumb. The whole part then attached to a plastic sheet and base is attached ply wood to keep it in position. 
The human hand glove consists of a triple axis accelerometer and five flex sensor attached to it to control the hand movement. The whole part then made wireless to enable it to be operate from a far off place by using a ZigBee transmitter- receiver module. From the block diagram in Fig. 4 and Figure. 5 it can be declared that when the user moves the arm or the fingers, the sensors fixed to the hand glove outputs an analog voltage. This analog voltage is given to the inbuilt ADC of the microcontroller. The processed digital signal is sent to the control circuitry of the robotic arm using the ZigBee transmitter module. The ZigBee receiver module then receives the digital values and they are use as the control signal to the servo motor. The servos then move the robotic arm to mimic the movement made by the user.

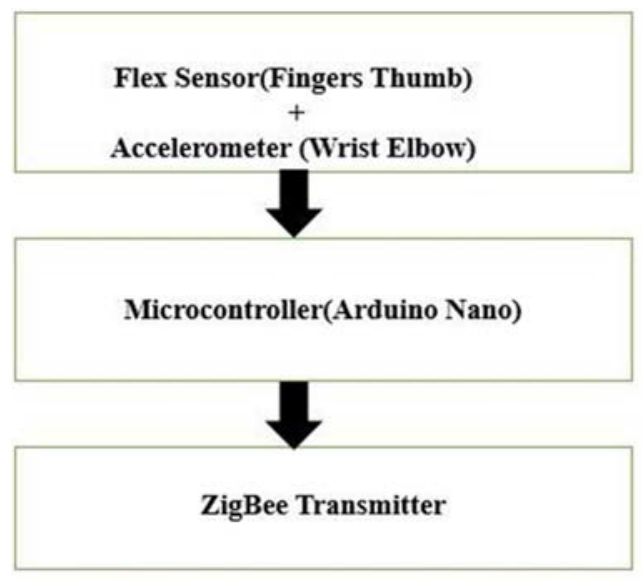

Figure 6. Block Diagram of Human Hand Glove.

\section{Results}

The performance of the robotic arm was checked using different hand movements. The design of the robotic arm is kept simple without the use of any gears or any complex mechanisms. The robotic arm was able to grasp light weight objects and also mimic the hand movements almost flawlessly. The use of the wireless module enabled to operate the robotic arm from a short distance of a few meters. The complete design of the hand glove is shown in Figure 8 .

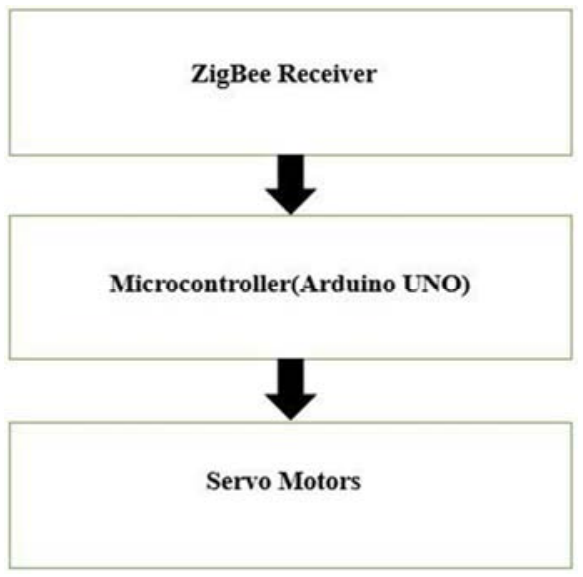

Figure 7. Block Diagram of Robotic Arm.

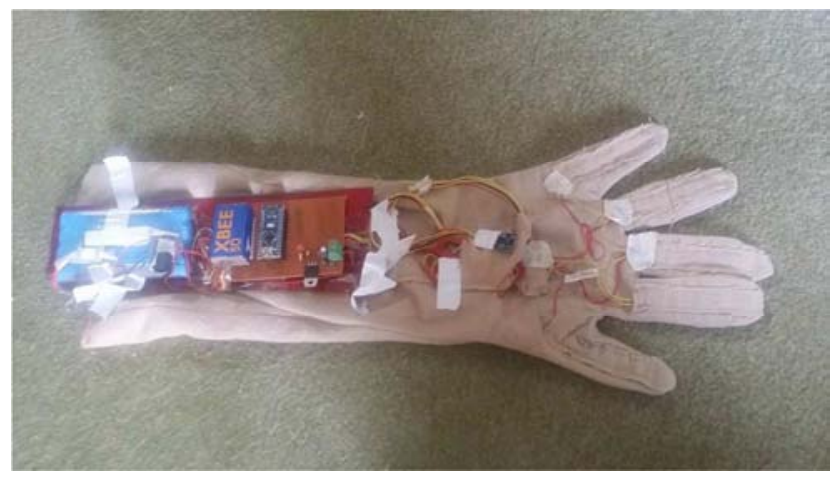

Figure 8. Complete Design of the human hand Glove.

Table 1. Different Technologies Overview.

\begin{tabular}{|c|c|c|c|c|c|}
\hline Sr.No & Author & Year & Technology & DOF & Wired/Wireless \\
\hline 1 & T. H. Soon et.al [32] & 1999 & VR TELEROBOT SYSTEM & NA & Wired \\
\hline 2 & J. G. Y. Shen et.al [33] & 2006 & Trajectory Planning & NA & Wired \\
\hline 4 & J. Lina, F. L. Lewisb et.al [35] & 2003 & fuzzy logic controller & NA & Wired \\
\hline 5 & S. C. Mukhopadhyay et.al [36] & 2009 & WiFi-based and Remote Vision & 3 & Wireless \\
\hline 6 & G. Carbone et.al [37] & 2010 & Service Tasks & 4 & Wireless \\
\hline 7 & K. Premkumar et.al [38] & 2015 & Smart phone based using raspberry pi, android and Wi-Fi & 3 & Wireless \\
\hline 8 & O. Olwan et.al [39] & 2014 & The Design and Analysis of Robotic Arm & 6 & Wired \\
\hline 9 & R. Szab, A. Gontean et.al [40] & 2013 & Remotely Commanding the Lynxmotion AL5 Type & 3 & Wireless \\
\hline 10 & R. K. Megalingam et.al [41] & 2012 & DTMF(Dual tone multi frequency) & NA & Wireless \\
\hline 11 & B. Varghese et.al [42] & 2015 & Wireless Control of Anthropomorphic & 7 & Wireless \\
\hline 12 & A. K. SANCHETI et.al [43] & 2012 & Gesture Actuated & 6 & Wireless \\
\hline 13 & A. Elfasakhany [44] & 2011 & Servo Motor & 4 & Wireless \\
\hline 15 & S. C. Mukhopadhyay et.al [46] & 2009 & Remote Vision & 3 & Wireless \\
\hline 16 & M. Quigley et.al [47] & 2012 & A Low-cost Compliant 7-DOF Robotic Manipulator & 7 & Wired \\
\hline 17 & A. M. Agas et.al [48] & 2015 & 3D Virtual Game for Facilitated Training & 3 & Wired \\
\hline
\end{tabular}




\section{Conclusion}

The paper presents a Gesture Control Robotic Arm Using Flex Sensor with seven degrees of freedom. The robotic arm was made of low cost materials that were readily available. The model of the robotic arm was constructed and the func- tionality was tested. The robotic arm can be controlled over the internet by using Ethernet connectivity and a camera for visual feedback.

\section{References}

[1] M. K. Habib, Mine Clearance Techniques and Technologies for Effective Humanitarian Demining, International Journal of Min Action, vol.6, no.1, 2002.

[2] M. K. Habib, and Y. Baudoin, Robot-Assisted Risky Intervention, Search, Rescue and Environmental Surveillance, Journal of Advanced Robotic Systems, vol. 7, no.1, pp. 1-8, 2010.

[3] KM. Z. Hussain and S. Karmorker. International conference on electrical engineering an information and communication technology (ICEEICT), IEEE (2014).

[4] A. Purohit, M. Kakatkar A 9-Dof Robotic Hand Teleoperation System Us- ing Haptic Technology in International Conference on Pervasive Com- puting (ICPC), 2015.

[5] L. Wang, Z. Deng, L. Zhang and Q. Meng, Dynamic Analysis of Reha- bilitative Arm Robot International Conference on Mechatronics and Automation, 2006.

[6] J. K. Paik, B. Shin, Y. Bang, Y. Shim, Development of an Anthropomorphic Robotic Arm and Hand for Interactive Humanoids Science Direct, Journal of Bionic Engineering, (2014).

[7] S. Klug, B. Mohl, O. v .Stryk and O. Barth, Design and application of a 3DOF Bionic Robot Arm, Proc. AMAM, 2005.

[8] T. Takaki, T. Omata, High-Performance anthropomorphic Robot Hand With Grasping-Force-Magnification Mechanism IEEE Transactions on- Mechatronics, 2011.

[9] J. SC, I. EK, K. DF, J. RT, B. KB Design of the Utah/MIT dexterous hand. In: Proceedings of the IEEE International Conference on Robotics and Automation. Spain; April 2005.

[10] Md. A. Rahman, A. H. Khan, Dr. T. Ahmed, Md. M. Sajjad Design, Analysis and Implementation of a Robotic Arm- The Animator American Journal of Engineering Research (AJER), 2013.

[11] A. R. Krishna, G. S. Bala, A. S. C. S. Sastry, B. B. P. Sarma, G. S. Alla, Design And Implementation Of A Robotic Arm Based On Haptic Technology International Journal of Engineering Research and Applications (IJERA) May-Jun 2012.

[12] V. J. Gohill, Dr. S. D. Bhagwat, A. P. Raut, P. R. Nirmal Robotics Arm Con- trol Using Haptic Technology International Journal of Latest Research in Science and Technology, March - April (2013).

[13] A. Che Soh, S. A. Ahmad, A. J. Ishak and K. N. A. Latif development of an adjustable gripper for robotic picking and placing operation international journal on smart sensing and intelligent systems, vol. 5, no. 4, december
2012.

[14] S. A. Khajone, Dr. S. W. Mohod, V. M. Harne Implementation of a Wireless Gesture Controlled Robotic Arm International Journal of Innovative Research in Computer and Communication Engineering, January 2015.

[15] V.Bhojak, G. K. Solanki, S. Daultani Gesture Controlled Mobile Robotic Arm Using Accelerometer International Journal of Innovative Research in Science, Engineering and Technology, June 2015.

[16] S. Jena, S. K. Nayak, S. K. Sahoo, S. R. Sahoo, S. Dash, S. K. Sahoo Interna- tional Journal Of Engineering Sciences \& Research Technology April, 2015.

[17] A. R. Al-Ali, M. A. Jarrah, R. Dhaouadi, Microcontrolleroperated an- thropomorphic manipulator with haptic feedback Robotics and Computer- Integrated Manufacturing 236370 (2007).

[18] D. K. Barbole, Dr. D. V. Jadhav Hand Gesture Recognition Using Flex Sensors International Engineering Research Journal (IERJ) Volume 1 Issue 8 Page 624-628, ISSN 23951621, 2015.

[19] N. Miller, O. C. Jenkins, M. Kallmann, M. J. MatariC Motion Capture From Inertial Sensing For Untethered Humanoid Teleoperation International Journal of Humanoid Robotics, June 24, 2004.

[20] R. Agrawal, K. Kabiraj, R. Singh Modeling a Controller for an Articulated Robotic Arm Intelligent Control and Automation, 3, 207-210, 2012.

[21] S. R. Nair Design of a Robotic Arm for Picking and Placing an Object Controlled Using LABView International Journal of Scientific and Research Publications, Volume 2, Issue 5, May 2012.

[22] R. K. Megalingam, T. P. kumar DTMF based Robotic Arm Design and Control for Robotic Coconut Tree Climber IEEE International Conference on Computer, Communication and Control (IC4-2015).

[23] S. Smith. Types of Robots [Online]. Available FTP: http://prime.jsc.nasa.gov/ROV/types.html. (2013).

[24] "The History and Benefits of Industrial Robots".UsedRobots.com. Re- trieved 2012-03-15.

[25] B. Malone, G. Devol: A Life Devoted to Invention, and Robots [Online]. Available FTP:

$\mathrm{http}: / /$ spectrum.iee.org/automaton/robotics/industrialrobots/george-devol-a-life-devoted-to-invention-androbots.(26Sep 2011).

[26] R. Padzensky GESTURE CONTROL [Online]. Available FTP: http://augmera.com/?p=546. (18 Apr 2015).

[27] A. I. Bhuyan, T. C. Mallick Gyro-accelerometer based control of a robotic Arm using AVR microcontroller Strategic Technology (IFOST), 2014 9th International Forum pages 409 413, 21-23 Oct. 2014.

[28] M. naveau, m.kudruss, o.stasse, c.kirches, k.mombaur, and p.soueres. A Reactive Walking Pattern Generator Based on Nonlinear Model Predictive Control. IEEE ROBOTICS AND AUTOMATION LETTERS, 2(2377- 3766), 10 - 17. 2016. 
[29] D. vershok, R. sadykhov, A. selikhanovich, K. schilling, H.roth. The Sys- temof Video-data Processing for the Autonomous Control of Mobile Robot. The System of Videodata Processing for the Autonomous Control of Mobile Robot, 2(0-7803-8138-6), 241 - 243. September 2003.

[30] Flex Sensor [Online]. Available https://cdn.sparkfun.com/datasheets/Sensors/ForceFlex/FLEX \%20SENSOR\%20DATA\%20SHEET\%202014.pdf.

[31] M. A. doshi, s. j. parekh, d. bhowmick. Wireless Robotic Hand Using Flex Sensors. International Journal of Scientific \& Engineering Research, 6(3), 1471-1475, March-2015.

[32] T. H. Soon, L. K. Hong "VR TELEROBOT SYSTEM" Proceedings of the 5th International Conference on Manufacturing Technology Beijing, 1st to 3rd November 1999.

[33] W. Shen, Y. Shen "Trajectory Planning for Tele-Robotic Skull Drill Sys- tem" IEEE International Conference on Information Acquisition, 20-23 Aug. 2006.

[34] Y. Jeong, Y. Lee “A 7 DOF wearable robotic arm using pneumatic actuators" Proceedings of the 32nd ISR (International Symposium on Robotics), 19-21 April 2001.

[35] J. Lin "Two-time scale fuzzy logic controller of flexible link robot arm" Fuzzy Systems, 2002. FUZZ-IEEE'02. Proceedings of the 2002 IEEE International Conference on 12-17 May 2002

[36] G. S. Gupta, S. C. Mukhopadhyay, M. Finnie "WiFi-based Control of a Robotic Arm with Remote Vision" nstrumentation and Measurement Technology Conference, 2009. I2MTC ’09. IEEE 5-7 May 2009.

[37] C. Castejn, G. Carbone, J. C. G. Prada, M. Ceccarelli "MultiObjective Opti- mization of a Robotic Arm for Service Tasks" Strojniki vestnik - Journal of Mechanical Engineering 56 (2010) 5, 316-329.

[38] K. Premkumar, K. G. J. Nigel "Smart phone based robotic arm control us- ing raspberry pi, android and Wi-F" Innovations in Information, Embedded and Communication Systems (ICIIECS), 2015 International Conference on 19-20 March 2015.

[39] O. Olwan, A. Matan; M. Abdullah; J. Abu-Khalaf "The Design and Anal- ysis of a Six-Degree of Freedom Robotic Arm" Mechatronics and its Applications (ISMA), 2015 10th International Symposium on 8-10 Dec. 2015.
[40] R. Szab, A. Gontean "Remotely Commanding the Lynxmotion AL5 Type Robotic Arms" Telecommunications Forum (TELFOR), 21st, 26-28 Nov. 2013.

[41] R. K. Megalingam, T. Pathmakumar; T. Venugopal; G. Maruthiyodan; A. Philip "DTMF based Robotic Arm Design and Control for Robotic Coconut Tree Climber" Computer, Communication and Control (IC4), 2015 International Conference on 10-12 Sept. 2015.

[42] B. Varghese, B. Thilagavathi "Design and Wireless Control of Anthro- pomorphic Robotic Arm" Innovations in Information, Embedded and Communication Systems (ICIIECS), 2015 International Conference on 19-20 March 2015.

[43] A. K. SANCHETI "Gesture Actuated Robotic Arm" International Journal of Scientific and Research Publications, Volume 2, Issue 12, December 2012.

[44] A. Elfasakhany, E. Yanez, K. Baylon, R. algado "Design and Development of a Competitive Low-Cost Robot" Modern Mechanical Engineering, 2011, 1, 47-55 doi:10.4236/mme.2011.12007 Published Online November 2011 .

[45] Mr. C. Chandra Mouli, Ms. P .Jyothi, Prof. K. Nagabhushan Raju, Prof. C. Nagaraja "Design of a Robotic Arm for Picking and Placing an Object Controlled Using LABView" IOSR Journal of Electrical and Electronics Engineering (IOSR-JEEE) e-ISSN: 2278-1676,p-ISSN: 2320-3331, Volume 6, Issue 5, PP 80-84, Jul. - Aug. 2013.

[46] G. S. Gupta, S. C. Mukhopadhyay; M. Finnie "WiFi-based Control of a Robotic Arm with Remote Vision" Instrumentation and Measurement Technology Conference, 2009. I2MTC '09. IEEE 5-7 May 2009.

[47] M. Quigley, A. Asbeck; A. Ng "A Low-cost Compliant $7-$ DOF Robotic Manipulator" Robotics and Automation (ICRA), 2011 IEEE International Conference on 9-13 May 2011.

[48] A. M. Agas, A. A. Daitol; U. B. Shah; L. J. Fraser; K. M. Abbruzzese; K. K. Karunakaran; R. Foulds "3-DOF Admittance Control Robotic Arm with a 3D Virtual Game for Facilitated Training of the Hemiparetic Hand" 2015 41st Annual Northeast Biomedical Engineering Conference (NEBEC) 17-19 April 2015. 